\title{
Psychometric Properties of the Persian Version of COVID Stress Scales (CSS) in the Iranian Population
}

\author{
Fereshte Momeni ( $\square$ momenipsy@gmail.com ) \\ University of Social Welfare and Rehabilitation Science https://orcid.org/0000-0003-1606-8387 \\ Mobina Hoseinpour Moqadam \\ University of Social Welfare and Rehabilitation Science \\ Mohammadreza Davoudi \\ University of Social Welfare and Rehabilitation Science \\ Nooshindokht MobarakAbadi \\ University of Social Welfare and Rehabilitation Science \\ Samaneh Hosseinzadeh \\ University of Social Welfare and Rehabilitation Science
}

\section{Research}

Keywords: Anxiety, COVID-19, Outbreak, Psychometric, Stress, Pandemic

Posted Date: April 26th, 2021

DOI: https://doi.org/10.21203/rs.3.rs-417409/v1

License: (c) (1) This work is licensed under a Creative Commons Attribution 4.0 International License. Read Full License 


\section{Abstract}

Background: Recently, 36-item COVID Stress Scales (CSS) was designed for assessing anxiety and stress related to COVID-19 outbreak. The present study aimed to evaluate the psychometric properties of the Persian version of CSS in the Iranian population.

Methods: A total of 393 participants volunteered to cooperate in the present study via an online survey. They completed a collection of scales, including the CSS, COVID-19 Phobia Scale (C19P-S), and Brief Symptom Inventory (BSI). The CSS reliability was determined by calculating Cronbach alpha and test-retest reliability. The validity assessed by Pearson correlation among the CSS and its subscales with C19P-S and BSI. Exploratory Factor Analysis (EFA) and Confirmatory factor analysis (CFA) was used to evaluate the structure of CSS. All analysis assessed by SPSS-26 software.

Results: Results showed that $45.3 \%$ of the participant's age were in $18-25$ years. Moreover, $72.8 \%$ of the participants were female. Also, Cronbach's alpha for all subscale was between 0.83 to 0.92 . The test-retest reliability coefficient of CSS was 0.87 . The correlation between the CSS, BSI and C19P-S showed that CSS has suitable convergent validity. CFA and EFA showed that the 5 -factor of CSS is the best model.

Conclusion: To conclude, Persian version of CSS has suitable psychometric properties for utilizing in Iranian population.

\section{Background}

From the first days emerging coronavirus disease 2019 (COVID-19) outbreak until November 1, 2020, more than forty-six million infected cases and 1.2 million deaths have been seen worldwide(1). In Eastern Mediterranean Region, Iran reporting the highest number of cases and deaths over the past week (1). During every epidemic, individuals have been faced with increasing susceptibility about psychological and mental health problems. Among psychiatric problems during viruses outbreaks, anxiety (or the lack thereof) is highly prevalent. About COVID-19, the result showed that one in four in the general population experienced significant levels of anxiety symptoms/disorder $(2,3)$. Very low levels of anxiety about being infected lead individual to negligence about hygiene behaviors, social distancing and reach out for receiving help(4). Also, those with severe levels of anxiety are more probable to experience panic, distress, and unnecessarily visiting doctors with every minor and usual sign $(5,6)$. During COVID-19 outbreaks, anxiety has various forms and dimensions. These dimensions include xenophobia, anxiety about socioeconomic consequences, traumatic stress symptom, compulsive sign checking, worries about disease danger and catastrophic contamination (7-9). Regarding these anxiety effects during COVID-19, it is widely known that all people need screening for COVID-19 anxiety and related issues. With this screening, specialists can identify people with very high/ low anxiety levels. For this extensive screening, face to face interview is dangerous (because of spreading virus) and requires exorbitant costs. To overcome these problems, one idea is to use simple self-assessment tools. Recently, a 36-item COVID Stress Scales (CSS) was developed for assessing anxiety during the COVID-19 outbreak. Beside common anxiety scales such as GAD-7 and GHQ-9, CSS was developed exclusively for the study of anxiety and distress for COVID-19 context. This scale assesses anxiety in five subscales including COVID danger and contamination, COVID socioeconomic consequences, COVID xenophobia, traumatic stress symptoms and COVID compulsive checking as well as total anxiety level (10). This scale showed suitable psychometric properties in the US and Canadian population. Based on our experiences in outpatient psychotherapy, many Iranian papulation have psychological distress related to infecting COVID. Regarding high rates of COVID infecting in Iran and high levels of stress and anxiety in Iranians (11), this study aimed to assess the psychometric properties of the Persian version of the COVID Stress Scales (CSS) in an Iranian community sample.

\section{Methods}

\section{Participants}

A total of 393 participants (minimum: 18 years) volunteered to take part in the current research via an online survey with a google form.

\section{Translate to Persian}

The 36-item COVID Stress Scales (CSS) reviewed and translated to Persian (formal Language in Iran) by a translator with a PhD in clinical psychology and collaborating with the corresponding author (psychologists). Then the original and translated versions of CSS was compared and approved by three PhD in clinical psychology. This CSS was given to 10 psychology students and invited them to answer the items. Then their comment received and implemented. Eventually, with the online focus group that was held, the CSS reviewed and approved.

\section{Measures}


Demographics variables: regarding socio-demographic features of the participants (e.g., age, sex, gender, and status) were involved in the online examination.

COVID Stress Scales (CSS): A 36 items scale for evaluation stress pertained to COVID-19. The CSS consists of the five-factor model COVIDrelated stress and includes fears about economic consequences, danger and contamination fears, compulsive checking and reassurance seeking, xenophobia, and traumatic stress symptoms related to COVID-19. The original version of the CSS showed suitable psychometric feature in American and Canadian papulation (10).

COVID-19 Phobia Scale (C19P-S): The C19P-S is a 20-items self-report tool with a five-point Likert-type scale to assess the levels of coronavirus (COVID-19) phobia. Items are rated between "strongly disagree (1)" to "strongly agree (5)." degree (points range is between 20 to 100). This instrument has three subscales, including psychological, Psychosomatic, and Economical. The sub-scales showed adequate internal consistency $(0.853<a<0.897)$, and Cronbach alpha for this tool was 0.926.(12).

Brief Symptom Inventory (BSI): The BSI designed to assessed nine dimensions of psychiatric symptoms (obsession-compulsion, somatization, interpersonal sensitivity, hostility, psychoticism, depression, anxiety, paranoid ideation, and phobic anxiety). This scale reflects three global indices. These synthetic indices are the General Severity Index (GSI), the Positive Symptom Distress Index, and the Positive Symptom Total. In more detail, the BSI is a self-report scales that use a five-point Likert scale, ranging from zero ("not at all") to four ("extremely"). Various researches showed that BSI has suitable psychometric properties in eastern and western countries such as Iran, US, Europe, Turkey and etc. $(13,14)$.

\section{Procedure}

After verification of the final Persian version of The CSS, we designed battery tests. This battery test includes CSS, Brief Symptom Inventory (BSI) and COVID-19 Phobia Scale (C19P-S). This battery tests transferred in the google form the GoogleForm link shared on social media (Instagram, WhatsApp, Telegram and LinkedIn). The online questionnaires took around 15 minutes to complete. The correlation of CSS with Brief Symptom Inventory (BSI) and COVID-19 Phobia Scale (C19P-S) used to assess convergent validity. For assessing reliability, test-retest reliability (retest reliability) used one week after the initial assessment. Data collection occurred from Jul to September 2020 . Inclusion criteria for volunteers were (I) at least 18 years old and (ii) Iranian citizenship. All the participators completed the survey anonymously and conferred their online consent.

\section{Statistical Analyses}

Data have been analyzed through SPSS (version 26) and LISREL (version8.8) software. For analyzing the data utilizing descriptive statistics (mean, standard deviation (SD), frequency and percentage) as well as Cronbach's alpha method to evaluate internal consistency. Pearson's coefficient was utilized to reliability and convergent correlation. To examine the latent structure of the Scale, EFA (IBM SPSS 23.0) and CFA (R 3.5.1, lavaan package) were used. The sample was randomly divided into two subsamples with size 196 and 197 . EFA was carried out using principal component analysis and varimax rotation method to allow correlations between the factors. Kaisere Meyere Olkin test (KMO) and Bartlett's Test were checked. In order to confirm the extracted factors, CFA was used. Appropriateness of model was assessed by the root mean square error of approximation (RMSEA) and standardized root mean square residual (SRMR) which should be smaller than .08, Bentler's Comparative Fit Index (CFI), which should be larger than .90 and Sattora-Bentler X2(S-B X2), which should not be statistically significant.

\section{Results}

\section{Descriptive measures}

This study was performed on 393 Iranian participants (more than 18 years old). $45.3 \%$ of participant's age were in $18-25$ years, $72.8 \%$ of the participants were female, and others were male.

\section{Internal Consistency}

For estimate the reliability index, the internal consistency was evaluated by the Cronbach's alpha method. After collecting the data, it was found that one of the items in the questionnaire was inadvertently removed due to its high similarity to the next item. This item was from the xenophobia subscale questions. Finally, the average of this subscale was replaced by this item. Cronbach's alpha coefficient assessed the 
internal consistency of factors; all of them were larger than 0.7 that showed good consistency. The results demonstrated that Cronbach's alpha method's internal consistency for all 36 items was 0.94 , and any questions (except 17th item) if removed, lead to decrease the value of alpha, which means that items are appropriate (Table 1). Examining the internal consistency of each of the subscales showed that the subscales have suitable internal consistency. The Cronbach's alpha for danger and contamination fears was 0.92 , for fears about economic consequences was 0.89 , for xenophobia" was 0.87 , for compulsive checking and reassurance-seeking was 0.9 , and for traumatic stress symptoms about COVID-19 was 0.83 . 
Table 1

Item-Total Statistics

\begin{tabular}{|c|c|c|c|c|}
\hline Items & $\begin{array}{l}\text { Scale Mean if Item } \\
\text { Deleted }\end{array}$ & $\begin{array}{l}\text { Scale Variance if Item } \\
\text { Deleted }\end{array}$ & $\begin{array}{l}\text { Corrected Item-Total } \\
\text { Correlation }\end{array}$ & $\begin{array}{l}\text { Cronbach's Alpha if Item } \\
\text { Deleted }\end{array}$ \\
\hline $\mathrm{A} 1$ & 45.0125 & 521.465 & .673 & .939 \\
\hline $\mathrm{A} 2$ & 44.6659 & 520.956 & .663 & .939 \\
\hline A3 & 44.4159 & 520.663 & .616 & .939 \\
\hline A4 & 44.6801 & 516.097 & .676 & .939 \\
\hline A5 & 45.3676 & 520.584 & .661 & .939 \\
\hline A6 & 45.4273 & 522.066 & .646 & .939 \\
\hline A7 & 46.4614 & 540.257 & .425 & .941 \\
\hline A8 & 46.5153 & 544.968 & .348 & .942 \\
\hline A9 & 46.1943 & 534.097 & .505 & .940 \\
\hline A10 & 45.9727 & 528.425 & .544 & .940 \\
\hline A11 & 46.6148 & 546.208 & .342 & .942 \\
\hline A12 & 45.6631 & 521.596 & .597 & .940 \\
\hline A13 & 45.8392 & 526.977 & .505 & .941 \\
\hline A14 & 45.6602 & 526.081 & .511 & .941 \\
\hline A15 & 45.6006 & 521.488 & .594 & .940 \\
\hline A16 & 45.6960 & 523.899 & .649 & .939 \\
\hline A17 & 45.3676 & 517.301 & .381 & .945 \\
\hline A18 & 46.0125 & 532.403 & .449 & .941 \\
\hline A19 & 44.6972 & 524.189 & .648 & .939 \\
\hline A20 & 44.6631 & 522.597 & .662 & .939 \\
\hline A21 & 45.2852 & 521.753 & .685 & .939 \\
\hline A22 & 44.7568 & 522.973 & .622 & .939 \\
\hline A23 & 44.9017 & 524.058 & .643 & .939 \\
\hline A24 & 45.1489 & 522.479 & .656 & .939 \\
\hline A25 & 46.2739 & 530.532 & .626 & .940 \\
\hline A26 & 46.3051 & 532.006 & .581 & .940 \\
\hline A27 & 46.5409 & 537.956 & .532 & .940 \\
\hline A28 & 46.4500 & 535.907 & .571 & .940 \\
\hline A29 & 46.5295 & 537.985 & .524 & .940 \\
\hline A30 & 46.7682 & 547.873 & .416 & .941 \\
\hline A31 & 45.8591 & 532.572 & .490 & .941 \\
\hline A32 & 45.8278 & 541.573 & .333 & .942 \\
\hline A33 & 46.4244 & 541.658 & .384 & .941 \\
\hline A34 & 45.8648 & 533.181 & .484 & .941 \\
\hline A35 & 45.3165 & 525.241 & .601 & .940 \\
\hline A36 & 45.5636 & 526.930 & .541 & .940 \\
\hline
\end{tabular}




\section{Test Retest Reliability}

Test-retest reliability (from 30 participants) with one week was assessed by intraclass correlation coefficient (ICC). The reliability coefficient of CSS was 0.87 .

\section{Validity}

In order to investigate the validity, the correlation between the CSS, and, Brief Symptom Inventory (BSI) and COVID-19 Phobia Scale (C19P-S) were calculated. As shown in Table 2, all convergent correlations are significant at the 0.01 level. Therefore, CSS and its subscales have appropriate Validity levels.

Table 2

Pearson's coefficient correlations among variables

\begin{tabular}{|c|c|c|c|c|c|c|c|c|c|c|c|c|c|c|c|c|}
\hline & & 2 & 3 & 4 & 5 & 6 & 7 & 8 & 9 & 10 & 11 & 12 & 13 & 14 & 15 & 16 \\
\hline 1 & CSS & .904 & .626 & .676 & .690 & .690 & .842 & .573 & .424 & .471 & .664 & .498 & .492 & .362 & .904 & .626 \\
\hline 2 & CSS. Danger & & .485 & .470 & .573 & .548 & .824 & .518 & .411 & .424 & .641 & .439 & .415 & .324 & .391 & .414 \\
\hline 3 & CSS. Fears & & & .290 & .326 & .322 & .497 & .301 & .235 & .297 & .345 & .330 & .284 & .240 & .220 & .253 \\
\hline 4 & $\begin{array}{l}\text { CSS. } \\
\text { Xenophobia }\end{array}$ & & & & .306 & .306 & .441 & .257 & .194 & .282 & .340 & .240 & .195 & .163 & .207 & .185 \\
\hline 5 & $\begin{array}{l}\text { CSS. } \\
\text { compulsive }\end{array}$ & & & & & .498 & .696 & .624 & .434 & .284 & .563 & .443 & .535 & .304 & .370 & .402 \\
\hline 6 & $\begin{array}{l}\text { CSS. } \\
\text { traumatic }\end{array}$ & & & & & & .578 & .447 & .253 & .323 & .533 & .327 & .463 & .244 & .327 & .332 \\
\hline 7 & C19P-S & & & & & & & .573 & .404 & .385 & .660 & .480 & .506 & .327 & .354 & .412 \\
\hline 8 & BSI. Anxiety & & & & & & & & .732 & .645 & .670 & .766 & .731 & .652 & .751 & .744 \\
\hline 9 & $\begin{array}{l}\text { BSI. } \\
\text { Depression }\end{array}$ & & & & & & & & & .610 & .539 & .762 & .537 & .801 & .796 & .640 \\
\hline 10 & $\begin{array}{l}\text { BSI. } \\
\text { Paranoid } \\
\text { Ideation }\end{array}$ & & & & & & & & & & .497 & .655 & .558 & .646 & .726 & .626 \\
\hline 11 & $\begin{array}{l}\text { BSI. Phobic } \\
\text { Anxiety }\end{array}$ & & & & & & & & & & & .565 & .561 & .500 & .516 & .552 \\
\hline 12 & BSI.OCD & & & & & & & & & & & & .658 & .734 & .757 & .685 \\
\hline 13 & $\begin{array}{l}\text { BSI. } \\
\text { Somatization }\end{array}$ & & & & & & & & & & & & & .555 & .543 & .593 \\
\hline 15 & $\begin{array}{l}\text { BSI. } \\
\text { Psychoticism }\end{array}$ & & & & & & & & & & & & & & .761 & .655 \\
\hline 15 & $\begin{array}{l}\text { BSI. } \\
\text { Interpersonal } \\
\text { Sensitivity }\end{array}$ & & & & & & & & & & & & & & & .750 \\
\hline 16 & BSI. Hostility & & & & & & & & & & & & & & & 1 \\
\hline
\end{tabular}

\section{Exploratory Factor Analysis (efa)}

The responses of the random subsample (196) were utilized for the evaluation of the EFA of CSS. KMO test showed very good sampling adequacy (0.885). Bartlett's Test was significant (chi-square value $=4637.76$, P-value $<0.05$ ) that explained the items are correlated and factor analysis can be fitted. Latent factors were obtained from the principal components analysis. The extracted factors were rotated with the varimax method. This criterion suggested the six-factor, which explained $70.05 \%$ of the variance (Table $3 \&$ Fig. 1 ). The pattern matrix of extracted factors is showed in Table 4. 
Table 3

Extracted principal components with Eigenvalues, Cumulative percentage of explained variance

\begin{tabular}{|llll|}
\hline Component & $\begin{array}{l}\text { Initial solution } \\
\text { Cumulative \% of } \\
\end{array}$ & Eigenvalue & Eigenvalue \\
\hline 1 & 36.100 & 36.100 & 4.799 \\
\hline 2 & 45.998 & 9.899 & 4.432 \\
\hline 3 & 54.194 & 8.196 & 4.191 \\
\hline 4 & 60.522 & 6.328 & 4.005 \\
\hline 5 & 66.286 & 5.765 & 3.605 \\
\hline 6 & 70.045 & 3.759 & 3.484 \\
\hline
\end{tabular}

Table 4

Pattern matrix of scale

\begin{tabular}{|llllllll|}
\hline \multicolumn{3}{|l}{ Components of anxiety } & \multicolumn{5}{c|}{ Components of anxiety } \\
\hline Item & 13 & 14 & 16 & Item & 11 & 12 & 15 \\
\hline 1 & & .534 & 18 & & .767 & \\
\hline 2 & & .628 & 19 & & .702 & \\
\hline 3 & & .824 & 20 & & .526 & \\
\hline 4 & & .804 & & 21 & & .785 & \\
\hline 5 & & .646 & & 22 & & .835 & \\
\hline 6 & & .583 & & 23 & & .804 & \\
\hline 7 & .829 & & & 24 & .837 & & \\
\hline 8 & .858 & & & 25 & .834 & & \\
\hline 9 & .844 & & & 26 & .850 & & \\
\hline 10 & .724 & & & 27 & .798 & & \\
\hline 11 & .752 & & & 28 & .711 & & \\
\hline 12 & .602 & & & 29 & .638 & & \\
\hline 13 & & & .676 & 30 & & & .760 \\
\hline 14 & & & .822 & 31 & & & .695 \\
\hline 15 & & & .801 & 32 & & & .809 \\
\hline 16 & & & .830 & 33 & & & .661 \\
\hline 17 & & & .794 & 34 & & & .613 \\
\hline & & & & 35 & & & .684 \\
\hline & & & & & & & \\
\hline
\end{tabular}

\section{Confirmatory Factor Analysis}

To confirm the latent structure of CSS, the CFA was evaluated. The analysis was carried out on the second subsample $(n=197)$. Factor solution with two to six factors was modelled to check if the 5 -factor is the best. Indicators of models were shown in Table 5. AIC, BIC, RMSEAand SRMR for the 5-factor model are smaller than other models and CFI is larger. Also, the model has the best indexes that show the five-factor extracted model is the best representation of the structure of the data. 
Table 5

indicators to comparing two- to six-factors models

\begin{tabular}{|lllllll|}
\hline No. of factors & S-Bx ${ }^{2}$ (df) & Robust CFI & Robust RMSEA $(90 \%$ Cl) & SRMR & AIC & BIC \\
\hline 6 factors & $1219.263(545)$ & 0.858 & $0.075(0.0680 .082)$ & 0.073 & 15612.708 & 15885.514 \\
\hline
\end{tabular}

\section{Discussion}

Also, they found that CSS has convergent and discriminant validity (10). These results are similar to previous studies that noted within long periods of infectious pandemics; various negative psychological states can influence mental health situation. (15, 16). The COVID-19 outbreak interrupts individual routines and consequently evokes anxiety and other psychological distress. On the other hand, it is usually noted in anecdotal experiences that individuals are scared of being infected with COVID-19(17). According to the results of the present questionnaire, this virus has led to mental distress in the occupational (fears about economic consequences), psychological (traumatic stress symptoms), and social fields 15,17 ). Also, individual with high levels of anxiety always worried about getting infected, so they keep themselves away from objects (compulsive checking and reassurance seeking), situations, and people (xenophobia) at risk. Because the virus can stay for a long time, the people with high levels of anxiety are afraid of everyone and is suspicious of all the people (especial from foreign persons) and objects (18). Furthermore, this anxiety has been linked to the stigmatization of citizens and everything about foreign. $(18,19)$. Also, people with high levels of anxiety often worried about getting infected and therefore try to reassurance by compulsive checking (20). Beside promising results of current research, the results of the current research have some limitations. First, the participants were a self-selected sample from the general population. Second, no formal diagnosis of anxiety disorders was undertaken. Finally, this study was cross-sectional, and we could not evaluate the causal effects of COVID on anxiety. Future studies can investigate the relationship between COVID-related anxieties with the possibility of infection. Moreover, the rate of COVID-related -in different at-risk groups (smokers, pregnant, addicts, diabetics, COPD and pre-existing respiratory conditions) should be compared with the general population.

\section{Conclusion}

Persian version of CSS has suitable psychometric properties for utilizing in Iranian population. This scale can assessing various levels of anxiety as a total measure. Also, CSS could evaluated various dimensions of COVID-related anxiety.

\section{Declarations}

Ethics approval and consent to participate: All procedures explained in the paper were in accordance with the ethical standards of the university of the social welfare and rehabilitation research committee, and with the 1964 Helsinki Declaration. All information anonymously collected and received participants contest

Consent to publish: We received consent for publication results from each participant.

Availability of data and material: Data of participants who consented to the public sharing of data are accessible from the first author upon reasonable demands.

Competing interests: The authors certify that they have no competing interests.

Funding: Nill.

Author's contributions: F.M and M.D. designed the first framework and analyzed the data. M.H.M and N.M. carried out the implementation. F.M. conducted the calculations. M.D, F.M and M.H.M wrote the manuscript with receiving help from N.M.

Acknowledgements: We would like to express our gratitude to the respected individulas who have cooperated in the implementation of this study.

Author's information: 1. Department of clinical psychology, University of Social Welfare and Rehabilitation Sciences, Tehran, Iran.

\section{References}

1. Organization WH. Weekly epidemiological update 3 November 2020 [Available from: https://www.who.int/publications/m/item/weeklyepidemiological-update--3-november-2020. 
2. Qiu J, Shen B, Zhao M, Wang Z, Xie B, Xu Y. A nationwide survey of psychological distress among Chinese people in the COVID-19 epidemic: implications and policy recommendations. General psychiatry. 2020;33(2).

3. Wang C, Pan R, Wan X, Tan Y, Xu L, Ho CS, et al. Immediate Psychological Responses and Associated Factors during the Initial Stage of the 2019 Coronavirus Disease (COVID-19) Epidemic among the General Population in China. International Journal of Environmental Research Public Health. 2020;17(5):1729.

4. Taylor S, Zvolensky MJ, Cox BJ, Deacon B, Heimberg RG, Ledley DR, et al. Robust dimensions of anxiety sensitivity: development and initial validation of the Anxiety Sensitivity Index-3. Psychol Assess. 2007;19(2):176-88.

5. Asmundson GJ, Taylor S. Coronaphobia. Fear and the 2019-nCoV outbreak. J Anxiety Disord. 2020;70:102196.

6. Arora A, Jha AK, Alat P, Das SS. Understanding coronaphobia. Asian Journal of Psychiatry. 2020;54:102384.

7. Salari N, Hosseinian-Far A, Jalali R, Vaisi-Raygani A, Rasoulpoor S, Mohammadi M, et al. Prevalence of stress, anxiety, depression among the general population during the COVID-19 pandemic: a systematic review and meta-analysis. Globalization health. 2020;16(1):1-11.

8. Pappa S, Ntella V, Giannakas T, Giannakoulis VG, Papoutsi E, Katsaounou P. Prevalence of depression, anxiety, and insomnia among healthcare workers during the COVID-19 pandemic: A systematic review and meta-analysis. Brain, behavior, and immunity. 2020.

9. da Silva FCT, Neto MLR. Psychiatric symptomatology associated with depression, anxiety, distress, and insomnia in health professionals working in patients affected by COVID-19: A systematic review with meta-analysis. Progress in NeuroPsychopharmacology and Biological Psychiatry. 2020:110057.

10. Taylor S, Landry C, Paluszek M, Fergus TA, McKay D, Asmundson GJ. Development and initial validation of the COVID Stress Scales. Journal of Anxiety Disorders. 2020:102232.

11. Moghanibashi-Mansourieh A. Assessing the anxiety level of Iranian general population during COVID-19 outbreak. Asian journal of psychiatry. 2020;51:102076.

12. Arpaci I, Karatas K, Baloglu M. The development and initial tests for the psychometric properties of the COVID-19 Phobia Scale (C19PS). Personality and individual differences. 2020:110108.

13. Al-Dweik G, AbuRuz ME. Validation of the Arabic Version of the Brief Symptom Inventory to Measure Anxiety in Patients With Acute Myocardial Infarction. Journal of nursing measurement. 2020.

14. Mohammadkhani P, Dobson KS, Amiri M, Ghafari FH. Psychometric properties of the Brief Symptom Inventory in a sample of recovered Iranian depressed patients. International journal of clinical health psychology. 2010;10(3):541-51.

15. Duncan LA, Schaller M, Park JH. Perceived vulnerability to disease: Development and validation of a 15-item self-report instrument. Personality Individual differences. 2009;47(6):541-6.

16. Pappas G, Kiriaze I, Giannakis P, Falagas M. Psychosocial consequences of infectious diseases. Clin Microbiol Infect. 2009;15(8):7437.

17. Li W, Yang Y, Liu ZH, Zhao YJ, Zhang Q, Zhang L, et al. Progression of Mental Health Services during the COVID-19 Outbreak in China. Int J Biol Sci. 2020;16(10):1732-8.

18. Pappas G, Kiriaze IJ, Giannakis P, Falagas ME. Psychosocial consequences of infectious diseases. Clinical microbiology and infection: the official publication of the European Society of Clinical Microbiology and Infectious Diseases. 2009;15(8):743-7.

19. Falagas ME, Kiriaze IJ. Reaction to the threat of influenza pandemic: the mass media and the public. Critical care (London, England). 2006;10(2):408.

20. Lee SA. How much "Thinking” about COVID-19 is clinically dysfunctional? Brain, behavior, and immunity. 2020.

\section{Figures}




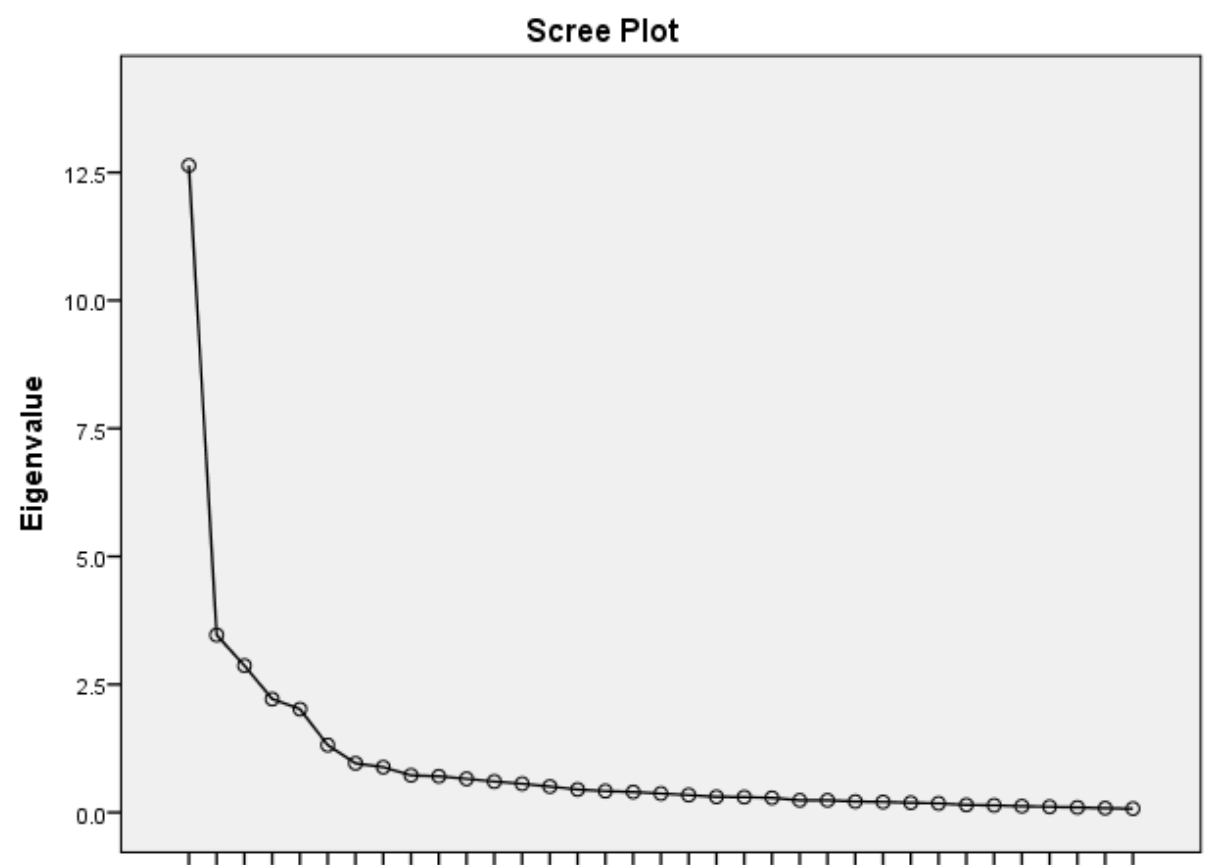

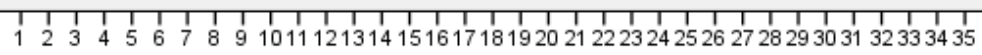

Component Number

Figure 1

scree plot to five factors extracted by EFA with eigenvalues larger than 1

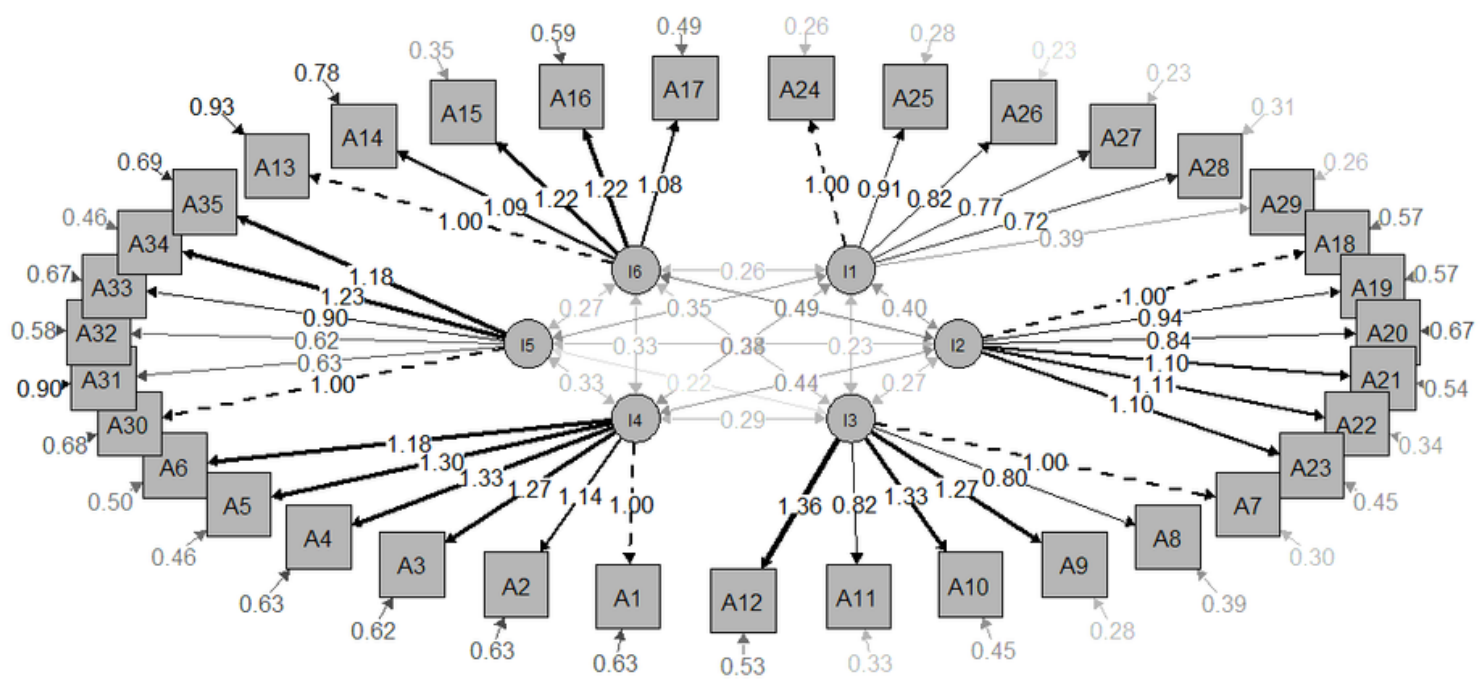

\section{Figure 2}

The best model fit for five-factor solution, the standardized parameter estimate 